\title{
Assessment of remodeling index and its relation to coronary heart disease in patients with types 2 diabetes by MDCT coronary angiography
}

\author{
Mansour Mohamed Mostafa Aref, Samy Hassan Nouh, Sameh Mosad Ibrahem, Wael Anwar Hasseb, \\ Ahmed Mohamed Mansour Eltantawy Mansour*
}

Department of Cardiology, Faculty of Medicine - Al-Azhar University

*Corresponding author: Ahmed Mohamed Mansour Eltantawy Mansour, Mobile: (+20) 01281012817,

E-Mail: dr_mansour2014@yahoo.com

\begin{abstract}
Background: Cardiovascular diseases (CVDs) are the primary cause of mortality worldwide with 17.3 million deaths per year and an estimation of 23.6 million in 2030, placing it as a relevant issue for the public health system.

Objectives: This study aimed to assess the Remodeling Index (RI) and its relation to coronary heart disease in patient with type 2 diabetes mellitus (T2DM) by multi-slice coronary CT angiography (MSCTA).

Patients and methods: This prospective observational study was conducted in Cardiology Department and Radiology Department in El-Agouza, Academy, Nasr City Police Hospital. The study included 250 patients with coronary remodeling of which 200 patients with type 2 diabetes (group I) and 50 are non-diabetics (group II) matched in age and sex with the patients' group I ( $>0.05)$. All patients referred for MSCT coronary angiography.

Results: As regard remodeling index of the two groups were $1.11 \pm 0.34$ and $0.81 \pm 0.29$ in groups (I) and (II), respectively. They showed a statistically highly significant difference between the two groups $(\mathrm{p}<0.001)$. The level of $<75$ th percentile was found in $74 \%$ and $100 \%$ of patients in groups (I) \& (II), respectively, while level of $>75$ th percentile was found in $26 \%$ of group (I) and not found in group (II) and they showed a statistically very highly significant difference $(\mathrm{p}<0.001)$.

Conclusion: Patients with T2DM are susceptible to premature CAD with more calcified and non-calcified plaques. Early prevention program using computed tomography angiography might be helpful in identifying diabetic patients with subclinical atherosclerosis.
\end{abstract}

Keywords: Remodeling Index, Coronary heart disease, Types 2 diabetes, MDCT coronary angiography

\section{Introduction}

Coronary heart disease (CHD) is the largest contributor of CVDs and mortality rate is due in prevalence to atherosclerosis, a chronic inflammatory condition of the arterial wall. Unfortunately, myocardial infarction (MI) is still a first common manifestation of CHD and, in about $50 \%$ of patients, angina pectoris is the first symptom of the pathology ${ }^{(1)}$.

Imaging techniques have deeply increased early detection of CHD, although the invasive approach restricts their feasibility mainly to symptomatic patients. Among them, for their higher spatial resolution, intravascular ultrasound (IVUS), X-ray angiography (XRA) and computed tomography coronary angiography (CTCA) provide a direct evaluation and quantification of coronary artery alteration, while cardiac magnetic resonance (CMR) and nuclear medicine techniques (single photon computed tomography (SPECT), and positron emission tomography (PET)) provide indirect information of $\mathrm{CHD}$, estimating myocardial perfusion and metabolism abnormalities that are consequent to coronary artery disease ${ }^{(2)}$.

Coronary computed tomography angiography (CTA) has been well established as a valuable non-invasive imaging modality for the diagnosis of coronary artery disease (CAD) with high accuracy and negative predictive value when compared to invasive coronary angiography (ICA) (3). Coronary CTA could also serve as a useful alternative to ICA for guidance of treatment in certain indications ${ }^{(4)}$. In addition, serum/plasma biomarkers can be mini-invasively extracted also in asymptomatic patients in order to analyze at different levels (e.g. cellular, biochemical, epigenetic and/or transcriptional) atherosclerosis and CHD development ${ }^{(5)}$. However, according to previous studies, the ability of coronary CTA to reliably assess luminal stenosis is significantly impaired in the presence of moderately to severely calcified lesions due to blooming and beam hardening artifacts, which make it difficult to clearly delineate the border between opacified lumen and calcium ${ }^{(6)}$. On a side note, the fact that 
coronary CTA is able to accurately characterize calcium burden has been used clinically to predict the requirement for rotational atherectomy during percutaneous coronary intervention ${ }^{(7)}$.

Vessel remodeling patterns of calcified lesions as evaluated by multi-slice coronary CT angiography (MSCTA) could potentially provide incremental value to the evaluation of stenotic severity. MSCTA appear to be of values of various morphological parameters of calcification, including the calcification remodeling index (RI), assessed by coronary CTA for predicting significant coronary stenosis with reference to ICA (8).

Type 2 diabetes mellitus (T2DM) is a major risk factor affecting coronary artery disease (CAD). In addition, $75 \%$ of T2DM patients die as a consequence of cardiovascular diseases, including CAD. In patients with T2DM, CAD is more likely to be a complex disease characterized by small, diffuse, calcified, multivessel disease (MVD) 3, 4) and often requires coronary revascularization in addition to optimal medical therapy to control angina ${ }^{(9)}$.

\section{Aim of the Work}

The aim of this study was to:

1- Perform assessment of Remodeling Index (RI) and its relation to coronary heart disease in patient with Type 2 Diabetes by multislice coronary CT angiography (MSCTA).

2- Detect the effect of type 2 diabetes mellitus (T2DM) on RI.

\section{Subjects and Methods}

This prospective observational study was conducted in Cardiology Department and Radiology Department in El-Agouza and Nasr City Police Academy Hospitals. The study included 250 patients with coronary remodeling of which 200 patients were diabetic type 2 and 50 were nondiabetic all 250 patients referred for MSCT coronary angiography in the period from November 2018 to November 2019.

Inclusion criteria: Adult patients of both genders aged more than 18 years old referred for multislice coronary computed tomography angiography (MS CCTA).

\section{Exclusion criteria:}

1- Previous acute or chronic renal failure had to be considered.
2- Patients with AF state and any other rhythm rather than sinus rhythm.

3- Patients with normal MSCT coronary angiography findings.

4- Patients with weight more than $150 \mathrm{~kg}$.

5- Patients with severe coronary artery calcium (CAC), defined as CAC scores above 400 to 1000.

6- History of CABG or previous PCI.

7- RWMA in echocardiography or EF $<50 \%$.

8- All vessels images with artefacts or improperly opacified.

Ethical approval and written informed consent:

An approval of the study was obtained from Al- Azhar University Academic and Ethical Committee. Every patient signed an informed written consent for acceptance of the operation.

\section{All patients were subjected to:}

1- History: History taking of age, gender, risk factors of HTN, smoking, DLP, family history of CAD. History taking of DM (duration of DM, type of DM, treatment of DM insulin or oral hypoglycemic treatment).

2- Clinical examination: Clinical examination including general and local examination blood pressure, body mass index and excluding other chronic illness.

3- Routine laboratory testing: Full laboratory investigation (complete lipid profile LDL, HDL, cholesterol, TGS, urea, creatinine, HBA1C, CBC).

4-ECG: 12 lead ECG was done to every patient by SCHILLER ECG device at speed $25 \mathrm{~mm} / \mathrm{sec}$, and voltage $1 \mathrm{mV}$ from the supine, resting patient by attaching an electrode to each of the four extremities and chest leads to exclude ischemic changes or AF state.

5-Echocardiography: Transthoracic echocardiography was done using Vivid 9 echocardiogram, including M-mode, 2D, PWD. The patient was lying on his left side, with the left arm widely abducted, parasternal long and short axis views were taken, also apical four chamber, apical five chamber and apical three chamber views were taken to assess ejection fraction (EF) by M-mode and by eyeballing, assessment of diastolic function by Mitral Inflow signal and to exclude RWMA. This was done according to American Society of Echocardiography (ASE).

4- MSCT Angiography: The Aquilion ONE 320 Slice CT is the most advanced CT system in the 
market. This dynamic volume CT in comparison to a 64-Slice, 128 slice or 256 slice CT scan can scan an entire organ in one single pass and produce 4D videos showing organ's structure, movement and blood flow. In addition, the system is fast enough to image the entire heart in less than a heartbeat, opening the door to accurate and safe imaging of patients with arrhythmia.

Patient preparation: Before starting MSCT coronary angiography full clinical examination, assessment of blood pressure, heart rate and routine cardiac examination were performed. All patients were instructed to remain fasting for about 4 hours before the scan. Patients were instructed as well to avoid coffee and tea drinks 24 hours before the study, to minimize their effects on the patients' heart rate.

Heart rate control: Patients with heart rate above $65 \mathrm{bpm}$ were given $5 \mathrm{mg}$ ivabradine, which can be repeated once to control heart rate.

Scan protocol and data interpretation: Patients were transferred to the scanning room, the procedure was explained to them, and ECG electrodes were placed to connect the patient continuous ECG monitoring. An IV access is secured (preferably an $18 \mathrm{G}$ cannula), The IV line was then connected to the dual head injector, and $50-70 \mathrm{ml}$ of contrast was then injected through the IV line using the dual head injector, followed by a $50 \mathrm{ml}$ of saline chaser. Assessment of the plaque causing positive remodeling regarding the site and number (single, kissing, or multiple). Specific measurements at the reference and remodeling segment were taken measuring plaque burden. Calculation of remodeling index will be done. Assessment of the effect of diabetes type 2 on the
RI and comparative groups were made between diabetic and non-diabetics.

\section{Statistical analysis:}

Recorded data were analyzed using the statistical package for social sciences, version 20.0 (SPSS Inc., Chicago, Illinois, USA). Quantitative data were expressed as mean \pm standard deviation (SD). Qualitative data were expressed as frequency and percentage.

\section{The following tests were done:}

- Independent-samples t-test of significance was used when comparing between two means.

- Chi-square $\left(\mathrm{x}^{2}\right)$ test of significance was used in order to compare proportions between two qualitative parameters.

- The confidence interval was set to $95 \%$ and the margin of error accepted was set to $5 \%$. The $\mathrm{p}$ value was considered significant as the following:

- Probability (P-value)

- P-value $<0.05$ was considered significant.

- P-value $<0.001$ was considered as highly significant.

- P-value > 0.05 was considered insignificant.

\section{Results}

This prospective observational study was conducted on 250 patients with coronary remodeling of which 200 patients were diabetic type 2 (group I) and 50 were non-diabetics (group II). All patients referred for MSCT coronary angiography and data are demonstrated.

Table (1): Comparison between group I (DM) and group II (Non-DM) according to demographic data

\begin{tabular}{|c|c|c|c|c|}
\hline Demographic data & $\begin{array}{c}\text { Group I: DM } \\
(n=200)\end{array}$ & $\begin{array}{c}\text { Group II: Non- } \\
\text { DM }(\mathbf{n}=\mathbf{5 0})\end{array}$ & $\mathbf{t} / \chi^{2 \#}$ & p-value \\
\hline $\begin{array}{ll}\text { Sex } & \\
\text { - Female } \\
\text { - } \\
\end{array}$ & $\begin{array}{c}65(32.5 \%) \\
135(67.5 \%)\end{array}$ & $\begin{array}{l}14(28.0 \%) \\
36(72.0 \%)\end{array}$ & $0.375^{\#}$ & 0.540 \\
\hline $\begin{array}{l}\text { Age (years) } \\
\qquad \quad \text { Mean } \pm \text { SD } \\
\text { - } \quad \text { Range }\end{array}$ & $\begin{array}{c}51.85 \pm 8.71 \\
31-67 \\
\end{array}$ & $\begin{array}{c}53.84 \pm 9.01 \\
34-67 \\
\end{array}$ & 2.068 & 0.152 \\
\hline
\end{tabular}

$t$-Independent Sample t-test; ${ }^{\#} x^{2}$ : Chi-square test

p-value >0.05 NS; *p-value <0.05 S; **p-value <0.001 HS

This table showed no statistically significant difference between group I: DM and group II: Non-DM according to age and sex. This indicated that the two groups are matched in age and sex.

Table (2): Comparison between group I and group II according to Plaque Burden (\%), Hemoglobin A1C, Cholesterol, Triglyceride, Low density lipoprotein (LDL) and High-density lipoprotein (HDL) 
ejhm.journals.ekb.eg

\begin{tabular}{|c|c|c|c|c|}
\hline & $\begin{array}{c}\text { Group I: } \\
\text { DM } \\
(n=200)\end{array}$ & $\begin{array}{l}\text { Group II: Non- } \\
\text { DM }(n=50)\end{array}$ & t-test & p-value \\
\hline $\begin{array}{cl}\text { Plaque Burden }(\%) \\
\bullet & \text { Mean } \pm \text { SD } \\
\bullet & \text { Range } \\
\end{array}$ & $\begin{array}{c}55.99 \pm 9.02 \\
40-77.3 \\
\end{array}$ & $\begin{array}{c}55.98 \pm 7.05 \\
45-71 \\
\end{array}$ & 0.000 & 0.996 \\
\hline $\begin{array}{c}\text { Hemoglobin A1C } \\
\bullet \quad \text { Mean } \pm \text { SD }\end{array}$ & $3.95 \pm 0.34$ & $2.52 \pm 0.79$ & 16.362 & $<0.001 * *$ \\
\hline $\begin{array}{cl}\text { Cholesterol } \\
\text { - } & \text { Mean } \pm \text { SD } \\
\text { - } & \text { Range }\end{array}$ & $\begin{array}{c}220.94 \pm 29.78 \\
130-300\end{array}$ & $\begin{array}{c}187.02 \pm 28.75 \\
140-243\end{array}$ & 52.606 & $<0.001 * *$ \\
\hline $\begin{array}{ll}\text { Triglyceride } \\
\qquad \quad \text { Mean } \pm \text { SD } \\
\bullet \quad \text { Range } \\
\end{array}$ & $\begin{array}{c}217.68 \pm 43.98 \\
124-452.2 \\
\end{array}$ & $\begin{array}{c}190.88 \pm 26.44 \\
142-230 \\
\end{array}$ & 16.999 & $<0.001 * *$ \\
\hline $\begin{aligned} & \text { LDL } \\
& \bullet \text { Mean } \pm \text { SD } \\
& \text { - } \text { Range } \\
&\end{aligned}$ & $\begin{array}{c}111.48 \pm 22.14 \\
72-194 \\
\end{array}$ & $\begin{array}{c}91.70 \pm 15.31 \\
75-128 \\
\end{array}$ & 35.582 & $<0.001 * *$ \\
\hline $\begin{array}{r}\text { HDL } \\
\bullet\end{array}$ & $43.40 \pm 9.64$ & $47.50 \pm 8.38$ & 2.080 & 0.151 \\
\hline
\end{tabular}

$t$-Independent Sample t-test;

p-value $>0.05 \mathrm{NS} ; * *$-value $<0.001 \mathrm{HS}$

This table and figure showed statistically significant difference between group I: DM and group II: Non-DM according to hemoglobin $\mathrm{A} 1 \mathrm{C}$, cholesterol, triglyceride and low-density lipoprotein.

Table (3): Comparison between group I: DM and group II: Non-DM according to Stenosis area (\%), Stenosis diameter (\%) and Length

\begin{tabular}{|c|c|c|c|c|}
\hline (2) & $\begin{array}{c}\text { Group I: DM } \\
(n=200)\end{array}$ & $\begin{array}{c}\text { Group II: Non- } \\
\text { DM }(n=50)\end{array}$ & t-test & p-value \\
\hline $\begin{array}{cl}\text { Stenosis area } \% \\
\text { - } & \text { Mean } \pm \text { SD } \\
\bullet & \text { Range } \\
\end{array}$ & $\begin{array}{c}39.33 \pm 22.24 \\
3-94\end{array}$ & $\begin{array}{c}39.09 \pm 19.40 \\
5-76\end{array}$ & 0.005 & 0.944 \\
\hline $\begin{array}{cl}\text { Stenosis diameter \% } \\
\text { - } & \text { Mean } \pm \text { SD } \\
\text { - } & \text { Range } \\
\end{array}$ & $\begin{array}{c}30.50 \pm 16.78 \\
7-94\end{array}$ & $\begin{array}{c}31.72 \pm 13.40 \\
10-61\end{array}$ & 0.230 & 0.632 \\
\hline $\begin{array}{cl}\text { Length } & \\
\bullet & \text { Mean } \pm \text { SD } \\
\bullet & \text { Range } \\
\end{array}$ & $\begin{array}{c}23.96 \pm 18.41 \\
10.2-95 \\
\end{array}$ & $\begin{array}{c}15.77 \pm 5.53 \\
7.8-32.2 \\
\end{array}$ & 9.659 & $0.002 *$ \\
\hline
\end{tabular}

t-Independent Sample t-test;

p-value >0.05 NS; *p-value $<0.05 \mathrm{~S}$

This table showed statistically significant difference between group I: DM and group II: Non-DM according to length.

Table (4): Comparison between $<75$ th Percentile and $\geq 75$ th Percentile of remodeling index according to demographic data in group I: DM

\begin{tabular}{|c|c|c|c|c|}
\hline \multirow[b]{2}{*}{ Demographic data } & \multicolumn{2}{|c|}{ Remodeling Index } & \multirow[b]{2}{*}{$\mathbf{t} / \chi^{2 \#}$} & \multirow[b]{2}{*}{ p-value } \\
\hline & $\begin{array}{c}<75^{\text {th }} \text { percentile } \\
\quad(n=148)\end{array}$ & $\begin{array}{c}\geq 75^{\text {th }} \text { percentile } \\
(n=52)\end{array}$ & & \\
\hline $\begin{array}{l}\text { Sex } \\
\text { Female } \\
\text { Male } \\
\end{array}$ & $\begin{array}{l}49(33.1 \%) \\
99(66.9 \%) \\
\end{array}$ & $\begin{array}{l}16(30.8 \%) \\
36(69.2 \%)\end{array}$ & 0.096\# & 0.757 \\
\hline $\begin{array}{l}\text { Age (years) } \\
\text { Mean } \pm \text { SD } \\
\text { Range }\end{array}$ & $\begin{array}{c}50.66 \pm 9.15 \\
31-67\end{array}$ & $\begin{array}{c}55.21 \pm 6.27 \\
41-66\end{array}$ & 11.017 & $<0.001 * *$ \\
\hline
\end{tabular}

t-Independent Sample t-test; \# $x^{2}$ : Chi-square test, **p-value <0.001 HS 
ejhm.journals.ekb.eg

This table shows statistically significant difference between group I: DM and group II: Non-DM according to age (years).

Table (5): Comparison between $<75$ th Percentile and $\geq 75$ th Percentile of remodeling index according to Plaque Burden (\%), Hemoglobin A1C, Cholesterol, Triglyceride, Low density lipoprotein, High density lipoprotein in group I: DM

\begin{tabular}{|c|c|c|c|c|}
\hline & \multicolumn{2}{|c|}{ Remodeling Index } & \multirow[b]{2}{*}{ t-test } & \multirow[b]{2}{*}{ p-value } \\
\hline & $\begin{array}{c}<75 \text { th Percentile } \\
(n=148)\end{array}$ & $\begin{array}{l}\geq 75 \text { th Percentile } \\
\quad(n=52)\end{array}$ & & \\
\hline $\begin{array}{cl}\text { Plaque Burden }(\%) \\
\text { - } & \text { Mean } \pm \text { SD } \\
\text { - } & \text { Range } \\
\end{array}$ & $\begin{array}{c}54.24 \pm 9.62 \\
40-77.3 \\
\end{array}$ & $\begin{array}{c}60.97 \pm 4.04 \\
50-68 \\
\end{array}$ & 23.915 & $<0.001 * *$ \\
\hline $\begin{array}{c}\text { Hemoglobin A1C } \\
\bullet \quad \text { Mean } \pm \text { SD }\end{array}$ & $3.50 \pm 0.08$ & $4.41 \pm 0.41$ & 2.602 & $0.010^{*}$ \\
\hline $\begin{aligned} & \text { Cholesterol } \\
& \text { - } \text { Mean } \pm \text { SD } \\
& \text { - } \text { Range } \\
&\end{aligned}$ & $\begin{array}{c}214.76 \pm 27.33 \\
130-300 \\
\end{array}$ & $\begin{array}{c}238.54 \pm 29.66 \\
192-300\end{array}$ & 27.855 & $<0.001 * *$ \\
\hline \begin{tabular}{ll} 
& \multicolumn{2}{l}{ Triglyceride } \\
$\bullet$ & Mean \pm SD \\
- & Range \\
\end{tabular} & $\begin{array}{c}214.12 \pm 45.02 \\
124-452.2 \\
\end{array}$ & $\begin{array}{c}227.83 \pm 39.55 \\
171-310\end{array}$ & 3.791 & $0.035^{*}$ \\
\hline $\begin{aligned} \text { LDL } & \\
\bullet & \text { Mean } \pm \text { SD } \\
\bullet & \text { Range }\end{aligned}$ & $\begin{array}{c}110.20 \pm 22.96 \\
72-194\end{array}$ & $\begin{array}{c}115.12 \pm 19.38 \\
89-153\end{array}$ & 1.902 & 0.169 \\
\hline $\begin{aligned} \text { HDL } & \\
\bullet & \text { Mean } \pm \text { SD }\end{aligned}$ & $43.28 \pm 9.94$ & $43.75 \pm 4.93$ & 0.022 & 0.882 \\
\hline
\end{tabular}

t-Independent Sample t-test

p-value $>0.05 \mathrm{NS}$; *p-value <0.05 S; **p-value <0.001 HS

This table showed statistically significant difference between group I: DM and group II: Non-DM according to plaque burden (\%), hemoglobin A1C, cholesterol and triglyceride.

Table (6): Comparison between $<75$ th Percentile and $\geq 75$ th Percentile of remodeling index according to electrocardiogram (ECG) in group I: DM.

\begin{tabular}{|c|c|c|c|c|}
\hline \multirow[b]{2}{*}{ ECG } & \multicolumn{2}{|c|}{ Remodeling Index } & \multirow[b]{2}{*}{$\chi^{2}$} & \multirow[b]{2}{*}{ p-value } \\
\hline & $\begin{array}{c}<75 \text { th Percentile } \\
(n=148)\end{array}$ & $\begin{array}{c}\geq 75 \text { th Percentile } \\
\quad(n=52)\end{array}$ & & \\
\hline Normal & $124(83.8 \%)$ & $36(69.2 \%)$ & \multirow{2}{*}{5.094} & \multirow{2}{*}{$0.024 *$} \\
\hline Sinus Tachycardia & $24(16.2 \%)$ & $16(30.8 \%)$ & & \\
\hline
\end{tabular}

$x^{2}$ : Chi-square test; *p-value $<0.05 \mathrm{~S}$

This table showed statistically significant difference between group I: DM and group II: Non-DM according to electro cardio gram.

Table (7): Comparison between $<75$ th Percentile and $\geq 75$ th Percentile of remodeling index according to normal vessels in group I: DM

\begin{tabular}{|c|c|c|c|c|}
\hline Remodeling Index & $\begin{array}{c}<75^{\text {th }} \text { percentile } \\
\quad(n=148)\end{array}$ & $\begin{array}{c}\geq 75^{\text {th }} \text { percentile } \\
(n=52)\end{array}$ & $\chi^{2}$ & p-value \\
\hline \multicolumn{5}{|l|}{ Normal vessels } \\
\hline - $\quad$ Doubled & $27(18.2 \%)$ & $15(28.8 \%)$ & \multirow{2}{*}{2.608} & \multirow{2}{*}{0.106} \\
\hline - $\quad$ Single & $121(81.8 \%)$ & $37(71.2 \%)$ & & \\
\hline \multicolumn{5}{|l|}{ Selected vessels } \\
\hline$\bullet \quad$ LAD & $118(79.7 \%)$ & $50(96.2 \%)$ & 6.55 & $0.011^{*}$ \\
\hline - $\quad$ LCX & $12(8.1 \%)$ & $0(0.0 \%)$ & 0.005 & 0.941 \\
\hline - $\mathrm{OM}$ & $3(2.0 \%)$ & $0(0.0 \%)$ & 0.731 & 0.393 \\
\hline - $\quad$ RCA & $15(10.1 \%)$ & $2(3.8 \%)$ & 0.015 & 0.902 \\
\hline
\end{tabular}

$x^{2}:$ Chi-square test; *p-value $<0.05 \mathrm{~S}$ 
ejhm.journals.ekb.eg

This table showed statistically significant difference between group I: DM and group II: Non-DM according to selected vessels of LAD.

Table (8): Comparison between $<75$ th Percentile and $\geq 75$ th Percentile of remodeling index according to Stenosis area (\%), Stenosis diameter (\%) and Length in group I: DM

\begin{tabular}{|c|c|c|c|c|}
\hline & \multicolumn{2}{|c|}{ Remodeling Index } & \multirow[b]{2}{*}{ t-test } & \multirow[b]{2}{*}{ p-value } \\
\hline & $\begin{array}{c}<75 \text { th } \\
\text { Percentile } \\
(n=148)\end{array}$ & $\begin{array}{c}\geq 75 \text { th } \\
\text { Percentile } \\
(n=52)\end{array}$ & & \\
\hline \multicolumn{5}{|l|}{ Stenosis area $(\%)$} \\
\hline - $\quad$ Mean \pm SD & $41.13 \pm 22.50$ & $34.21 \pm 20.86$ & \multirow{2}{*}{3.774} & \multirow{2}{*}{$0.044 *$} \\
\hline - Range & $4-94$ & $3-74$ & & \\
\hline \multicolumn{5}{|c|}{ Stenosis diameter $(\%)$} \\
\hline - $\quad$ Mean \pm SD & $31.45 \pm 17.89$ & $27.77 \pm 12.87$ & \multirow{2}{*}{1.863} & \multirow{2}{*}{0.174} \\
\hline - Range & $7-94$ & $12-61$ & & \\
\hline \multicolumn{5}{|l|}{ Length } \\
\hline - $\quad$ Mean \pm SD & $24.08 \pm 17.27$ & $23.61 \pm 21.51$ & \multirow{2}{*}{0.026} & \multirow{2}{*}{0.873} \\
\hline - Range & $10.2-75$ & $10.9-95$ & & \\
\hline
\end{tabular}

t-Independent Sample t-test;

p-value $>0.05 \mathrm{NS}$; *p-value $<0.05 \mathrm{~S}$

This table showed statistically significant difference between group I: DM and group II: Non-DM according to stenosis area $(\%)$.

Table (9): Correlation between remodeling index with all parameters, using Pearson Correlation coefficient in group I: DM

\begin{tabular}{|l|c|c|}
\hline Remodeling Index & r & p-value \\
\hline Age (years) & 0.385 & $<0.001 * *$ \\
\hline Duration of DM & 0.466 & $<0.001^{* *}$ \\
\hline Plaque Burden (\%) & 0.151 & $0.029 *$ \\
\hline Hemoglobin A1C & 0.317 & $0.037 *$ \\
\hline Cholesterol & 0.486 & $<0.007^{* *}$ \\
\hline Triglyceride & 0.250 & $<0.001^{* *}$ \\
\hline Low density lipoprotein & 0.133 & 0.060 \\
\hline High density lipoprotein & -0.068 & 0.336 \\
\hline LVEF (\%) & -0.105 & 0.137 \\
\hline Wall/Lumen ratio (\%) & 0.513 & $0.043 *$ \\
\hline Stenosis area (\%) & -0.263 & $<0.001 * *$ \\
\hline Stenosis diameter (\%) & -0.153 & $0.030^{*}$ \\
\hline Length & -0.072 & 0.313 \\
\hline
\end{tabular}

$r$-Pearson Correlation Coefficient

p-value $>0.05 \mathrm{NS} ; *$ p-value $<0.05 \mathrm{~S} ; * *$-value $<0.001 \mathrm{HS}$

Positive correlation and significance between remodeling index with age, duration of DM, plaque burden, cholesterol, hemoglobin A1C, triglyceride and wall/lumen ratio, while stenosis area (\%) and stenosis diameter $(\%)$ showed significant negative correlation.

\section{DISCUSSION}

The objective of this study was to assess the Remodeling Index (RI) and its relation to coronary heart disease in patient with type 2 diabetes mellitus by multi-slice coronary CT angiography (MSCTA). The study was conducted on 250 patients with coronary remodeling of which 200 patients with type 2 diabetes (group I) and 50 are non-diabetics (group II) matched in age and sex with patients of group I $(\mathrm{P}>0.05)$. All patients referred for MSCT coronary angiography.

In a study on 1,635 young subjects undergoing coronary CTA from the registry, diabetes was a strong predictor of having any coronary plaque among the asymptomatic population (odds ratio $3.31,95 \%$ CI 1.19 to $9.21, \mathrm{p}$ $<0.02)^{(10)}$. Madaj et al. ${ }^{(11)}$ previously found a $57.5 \%$ prevalence of CAD detected by computed 
tomography in a cross-sectional small study on 40 young DM. Nezarat et al. ${ }^{(12)}$ showed the similarity of the presence of CAD among young patients with T2DM, which was significantly greater than patients without diabetes even after adjusting for classical risk factors (58\% vs 20\%). These studies have also demonstrated that young patients with T2DM had more non-calcified plaque compared to non-diabetic patients.

Risk factors of the two groups were statistically insignificant $(p>0.05)$ as regard smoking habit and family history, while they were statistically significant $(\mathrm{p}<0.001)$ as regards hypertension, i.e. hypertension was more pronounced risk factor in diabetic patients' group (group I). Ju and Choi ${ }^{(\mathbf{1 3})}$ concluded that the latent types of risk factors for coronary artery disease were smoking, dyslipidemia, metabolic syndrome and diabetes group were the high-risk groups. Family history and genetics are common risk factors also for CAD ${ }^{(14)}$. Although several studies have rejected the theory of equivalency of diabetes with $\mathrm{CAD}$, diabetes is introduced as a complex chronic illness and we could not ignore the major impact of diabetes to the cardiovascular system ${ }^{(\mathbf{1 5})}$. There are no adequate data for the management of young T2DM in the current guidelines. The cut point for presenting the coronary atherosclerosis in Nezarat et $\boldsymbol{a l} .{ }^{(12)}$ study was 25.2 years and they highly suggest using noninvasive CCTA in young $\mathrm{T} 2 \mathrm{DM}$ and more longitudinal outcome studies to prove the benefit of medical anti atherosclerotic treatment in their population.

The combination of coronary heart disease and diabetes mellitus type 2 with multivascular lesions of coronary arteries was associated with an increase in triglycerides, lipoprotein cholesterol of very low density that influences greatly on the progression of coronary atherosclerosis with lesions of greater number of coronary arteries at patients surveyed. At patients with coronary heart disease and diabetes mellitus type 2 with multivascular lesions of coronary arteries, the left ventricle myocardial re-modeling occurred through the increase of left ventricle's size and cavity ${ }^{(16)}$.

In the present study, it was found that plaque burden $(\%)$ was not statistically significant between the two groups ( $\mathrm{P}>0.05$ ). Hemoglobin A1c, cholesterol, triglycerides and LDLcholesterol were found to be statistically highly significant $(\mathrm{P}<0.001)$ in comparison with the nondiabetic groups, while HDL-cholesterol was found to be non-significant. There is an established link between hyperglycemia, coronary artery calcification (CAC), and diagnostic glycated $\mathrm{HbA1c}$ as a predictor of cardiovascular disease ${ }^{(17)}$. In fact, epidemiological evidence supports a greater risk for atherosclerotic coronary vascular disease with increasing dysglycemia, with an estimated $11 \%$ to $16 \%$ increase in cardiovascular events for every $1 \%$ increase in $\mathrm{HbAlc}{ }^{\left({ }^{(18)}\right.}$.

Yahagi et al. ${ }^{(19)}$ showed that the internal elastic lamina (IEL) area (a histologic indicator of vessel size), when adjusted for the distance from the coronary ostium, is greater in subjects with T1D and T2D relative to those without diabetes $\left(\mathrm{T} 1 \mathrm{D}=18.2 \pm 6.6 \mathrm{~mm}^{2}, \mathrm{~T} 2 \mathrm{D}=16.5 \pm 4.4 \mathrm{~mm}^{2}\right.$ vs. non-diabetic $=16.0 \pm 4.5 \mathrm{~mm}^{2}, \mathrm{P}=0.001$ and $\mathrm{P}=$ 0.01 , respectively). Also, Virmani et al. (20) reported similar results.

According to left ventricular ejection fraction (LVEF\%) and regional wall motion abnormality, we found that LVEF\% was statistically insignificant $(\mathrm{P}>0.05)$ in comparison with the non-diabetic group, while wall/lumen ratio showed a statistically significant difference $(\mathrm{p}=$ 0.023). In contrast to this study, Ehl et al. (21) demonstrated a significantly lower LVEF in diabetic compared to non-diabetic patients $(\mathrm{P}=0.001)$ in a large patient population. Even though the difference was small. This finding might have important epidemiological impact, since LVEF is one of the most important predictors of survival. This hypothesis is supported by data from the Mayo clinic that has demonstrated a significantly worse survival of even asymptomatic diabetic patients with LVEF $<50 \%{ }^{(22)}$.

Bouthoorn et al. ${ }^{(15)}$ is the first to provide pooled estimates of the prevalence of left ventricular diastolic dysfunction (LVDD) among type 2 diabetes patients and demonstrated that LVDD is an important problem among men and women with type 2 diabetes, affecting on average $35 \%$ (95\% CI: $24 \%-46 \%$ ) of type 2 diabetes patients in the community and $48 \%$ (95\% CI: $38 \%-$ $59 \%$ ) of type 2 diabetes patients in the hospital population.

As regards stenosis area and diameter, they had a statistically insignificant difference ( $p$ > 0.05 ), while stenosis length showed a statistically highly significant value $(\mathrm{P}=0.002)$.

Remodeling Index is a novel index that has been proposed in this current study in order to evaluate the stenosis extent of calcified coronary lesions. According to our findings, calcification RI strongly correlated with stenosis extent as determined by MSCT angiography which is parallel to the findings by $\mathbf{Y u}$ et $\boldsymbol{a l}{ }^{\left({ }^{(8)}\right.}$ determined 
by ICA and they outperformed other parameters such as per-lesion calcium volume and Agatston score as well as calcification length to predict severe coronary stenosis. Although the histological correlation of this calcification remodeling pattern remains unknown, they hypothesized that it could potentially represent the different locations of calcium deposits. As revealed by intravascular ultrasound (IVUS), calcium location is defined as superficial if present in the intimal-luminal interface and deep if within the medial-adventitial border or closer to the adventitia than the lumen ${ }^{(23)}$. Due to its limited spatial resolution, coronary CTA is not able to accurately locate calcium deposits on cross-sectional images. However, Yu et al. ${ }^{\left({ }^{(8)}\right.}$ think that calcification with significant negative remodeling could be predominantly intimallocated, which might protrude into the coronary lumen and subsequently cause severe lumen loss.

As regards remodeling index, it was 1.11 \pm 0.34 and $0.81 \pm 0.29$ for groups (I) and (II), respectively. They showed a statistically highly significant difference between the two groups $(\mathrm{p}<$ 0.001 ). The level of $<75$ th percentile was found in $74 \%$ and $100 \%$ of patients in groups (I) \& (II), respectively, while level of $>75$ th percentile was found in $26 \%$ of group (I) and not found in group (II) and they showed a statistically very highly significant difference $(\mathrm{p}<0.001)$.

Funck et al. (24) found that calcified plaque volumes were higher in patients with type 2 diabetes without a history of CVD compared to controls. The observed difference seemed to be driven primarily by the extent and proximal localization of atherosclerosis (higher number of proximal coronary segments with plaque involvement and longer plaque length). Also, the number of plaques associated with high risk (spotty calcifications and remodeling index >1.1) was higher for patients with type 2 diabetes.

In the present study, we found that the RI of moderately or severely calcified coronary lesions is inversely correlated with the stenosis extent as determined by MSCTA. This is in agreement with Yu et al. ${ }^{\left({ }^{(8)}\right.}$ study, which had a cutoff value of 0.94 , calcification RI is the strongest independent predictor of coronary stenosis $\geqq 70 \%$ and determined by ICA. In comparison between stenotic extent $<75$ th percentile and $\geq 75$ th percentile of remodeling index according to sex, it showed a statistically non-significant difference, while in comparison with age group, duration of diabetes, smoking, family history and hypertension as a risk factors, they showed a statistically highly significant difference $(\mathrm{p}<0.001)$. In comparison between them as regard plaque burden, HbA1c, total cholesterol, and triglycerides, they all showed a statistically significant difference, while LDL and HDL showed non-significant difference. Also, in comparison between them as regard LVEF\% and regional wall motion, they were statistically insignificant, while wall/lumen ratio was statistically significant $(\mathrm{p}=0.045)$.

CTCA has overcome several of previous technique drawbacks, allowing an accurate quantitative evaluation of the arterial lumen, vessel wall and the extension, severity and composition of the atherosclerotic plaque ${ }^{(25)}$. A first level of evidence that can be extracted by CTCA is represented by the detection of coronary calcium deposits and the assessment of lumen stenosis ${ }^{(5)}$.

Calcium burden is usually quantified using the 'Agatston score', an aggregate score across entire vessel territories rather than across specific atherosclerotic plaques, and mainly related to risk stratification of asymptomatic patients (26), than of symptomatic ones ${ }^{(27)}$.

Pop-Busui et al. ${ }^{(28)}$ in a large cohort of patients with T2DM and moderate to severe CAD reported that those treated with insulin had fewer highly stenotic coronary narrowing and lower myocardial jeopardy indices compared to those not treated with insulin. Also, subjects treated with thiazolidinediones (TZDs) had a fewer highly stenotic narrowing compared to those not taking TZDs. These differences remained significant after adjustment for traditional cardiovascular risk factors such as age, gender, lipids, and hypertension. Although insulin use and TZD use were associated with remarkably different levels of inflammatory markers, each drug was independently associated with less severe narrowing of coronary arteries as measured by coronary angiography.

\section{Conclusions and Recommendations}

In association with imaging improvements, novel high-throughput platforms investigating proteomic, metabolomic, epigenomic, and transcriptomics profiles together with genome-wide association studies may generate "multimarker CHD scores" with a higher predictive power than the use of a single biomarker. Surrogate biomarkers of coronary atherosclerosis and advanced imaging techniques could represent important cornerstones to characterize sub-clinical and clinical 
atherosclerosis with a consequent facilitation in the decision-making and clinical management of patients.

Patients with T2DM are susceptible to premature $\mathrm{CAD}$ with more calcified and noncalcified plaques. Early prevention program using computed tomography angiography might be helpful in identifying diabetic patients with subclinical atherosclerosis.

Future studies with functional validation are required to determine the relationship of this anatomical index with hemodynamical status.

\section{References}

1. Dalen JE, Alpert JS, Goldberg RJ, Weinstein RS (2014): The epidemic of the 20(th) century: coronary heart disease. Am J Med., 127 (9): 807-12.

2. Schuijf JD, Shaw LJ, Wijns W, Lamb HJ, Poldermans D, de Roos A, van der Wall EE, Bax JJ (2005): Cardiac imaging in coronary artery disease: differing modalities. Heart, 91: 1110-1117.

3. Li Y, Zhang J, Lu Z, Pan J (2012): Discrepant findings of computed tomography quantification of minimal lumen area of coronary artery stenosis: correlation with intravascular ultrasound. Eur J Radiol., 81: 3270-3275.

4. Zhang J, Li Y, Li M, Pan J, Lu Z (2014): Collateral vessel opacification by computed tomography in patients with coronary total occlusion and its relation with downstream myocardial infarction. Radiology, 271: 703-710.

5. Infante T, Forte E, Schiano C, Cavaliere C, Tedeschi C, Soricelli A, Salvatore M, Napoli C (2017): An integrated approach to coronary heart disease diagnosis and clinical management. Am J Transl Res., 9 (7): 3148-3166.

6. Vavere AL, Arbab-Zadeh A, Rochitte CE et al. (2011): Coronary artery stenoses: accuracy of 64-detector row CT angiography in segments with mild, moderate, or severe calcification-a subanalysis of the CORE-64 trial. Radiology, 261: 100-108.

7. Sekimoto T, Akutsu Y, Hamazaki Y et al. (2016): Regional calcified plaque score evaluated by multidetector computed tomography for predicting the addition of rotational atherectomy during percutaneous coronary intervention. $\mathbf{J}$ Cardiovasc Comput Tomogr., 10: 221228.
8. Yu M, Li Y, Li W, Lu Z, Wei M, Zhang J (2018): Calcification remodeling index assessed by cardiac CT predicts severe coronary stenosis in lesions with moderate to severe calcification. $\mathrm{J}$ Cardiovasc Comput Tomogr., 12 (1): 42-49.

9. Naito $R$ and Miyauchi $K$ (2017): Coronary Artery Disease and Type 2 Diabetes Mellitus. Int Heart J., 58 (4): 475480.

10. Otaki Y, Gransar H, Cheng VY et al. (2015): Gender differences in the prevalence, severity, and composition of coronary artery disease in the young: a study of 1635 individuals undergoing coronary CT angiography from the prospective, multinational confirm registry. Eur Heart J Imaging, 16: 490e499.

11. Madaj PM, Budoff MJ, Li D, Tayek JA, Karlsberg RP, Karpman HL (2012): Identification of noncalcified plaque in young persons with diabetes: an opportunity for early primary prevention of coronary artery disease identified with low-dose coronary computed tomographic angiography. Acad Radiol., 19: 889e893.

12. Nezarat N, Budoff MJ, Luo $Y$ et al. (2017): Presence, characteristics, and volumes of coronary plaque determined by computed tomography angiography in young type 2 diabetes mellitus. Am J Cardiol., 119 (10): 1566-1571.

13. Ju E, Choi J (2017): Identifying latent classes of risk factors for coronary artery disease. J Korean Acad Nurs., 47 (6): 817 827.

14. Hamrefors V (2017): Common genetic risk factors for coronary artery disease: new opportunities for prevention? Clin Physiol Funct Imaging, 37 (3): 243-254.

15. Bouthoorn S, Valstar GB, Gohar A, den Ruijter HM, Reitsma HB, Hoes AW, Rutten FH (2018): The prevalence of left ventricular diastolic dysfunction and heart failure with preserved ejection fraction in men and women with type 2 diabetes: A systematic review and meta-analysis. Diab Vasc Dis Res., 15 (6): 477-493.

16. Sypalo A, Kravchun P, Kadykova $O$ (2017): The influence of mono- and multivascular lesions of coronary arteries on the course of coronary heart disease in patients with diabetes mellitus type 2 . Georgian Med News, (264):61-65.

17. Jung CH, Rhee EJ, Kim KJ et al.(2015): Relationship of glycated hemoglobin A1c, coronary artery calcification and insulin 
resistance in males without diabetes. Arch Med Res., 46: 71-77.

18. Holman RR, Paul SK, Bethel MA, Matthews DR, Neil HA (2008): 10-year follow-up of intensive glucose control in type 2 diabetes. N Engl J Med., 359: 15771589.

19. Yahagi K, Kolodgie FD, Lutter C, Mori H, Romero ME, Finn AV, Virmani R (2017): Pathology of Human Coronary and Carotid Artery Atherosclerosis and Vascular Calcification in Diabetes Mellitus. Arterioscler Thromb Vasc Biol., 37 (2): 191-204.

20. Virmani R, Burke AP, Farb A, Kolodgie FD (2006a): Pathology of the vulnerable plaque. J Am Coll Cardiol., 47 (8): C13C18.

21. Ehl NF, Kühne M, Brinkert M, MüllerBrand J, Zellweger MJ (2011): Diabetes reduces left ventricular ejection fraction-irrespective of presence and extent of coronary artery disease. Eur J Endocrinol., 165 (6): 945-51.

22. Chareonthaitawee $P$, Sorajja $P$. Rajagopalan N. Miller TD, Hodge DO. Frye RL, Gibbons RJ (2007): Prevalence and prognosis of left ventricular systolic dysfunction in asymptomatic diabetic patients without known coronary artery disease referred for stress single-photon emission computed tomography and assessment of left ventricular function. American Heart Journal, 154: 567-574.

23. Madhavan MV, Tarigopula M, Mintz GS, Maehara A, Stone GW, Généreux P (2014): Coronary artery calcification: pathogenesis and prognostic implications.

J Am Coll Cardiol., 63: 1703-14.

24. Funck KL, Laugesen E, Øvrehus K, Jensen JM, Nørgaard BL, Dey D, Hansen TK, Poulsen PL (2017): Increased high-risk coronary plaque burden is associated with arterial stiffness in patients with type 2 diabetes without clinical signs of coronary artery disease: a computed tomography angiography study. J Hypertens., 35 (6): 1235-1243.

25. Forte E, Inglese $M$, Infante T, Schiano C, Napoli C, Soricelli A, Salvatore M, Tedeschi C (2016): Anomalous left main coronary artery detected by CT angiography. Surg Radiol Anat., 38: 987990.

26. Greenland P, Bonow RO, Brundage BH, Budoff MJ, Eisenberg MJ et al. (2007): ACCF/AHA 2007 clinical expert consensus document on coronary artery calcium scoring by computed tomography in global cardiovascular risk assessment and in evaluation of patients with chest pain: a report of the American college of cardiology foundation clinical expert consensus task force (ACCF/AHA writing committee to update the 2000 expert consensus document on electron beam computed tomography) developed in collaboration with the society of atherosclerosis imaging and prevention and the society of cardiovascular computed tomography. J Am Coll Cardiol., 49: 378402.

27. Marwan M, Ropers D, Pflederer T, Daniel WG, Achenbach S (2009): Clinical characteristics of patients with obstructive coronary lesions in the absence of coronary calcification: an evaluation by coronary CT angiography. Heart, 95: 1056-1060.

28. Pop-Busui R, Lombardero M, Lavis V, Forker A, Green J, Korytkowski M, Sobel BE, Jones TL (2009): Relation of severe coronary artery narrowing to insulin or thiazolidinedione use in patients with type 2 diabetes mellitus (from the Bypass Angioplasty Revascularization Investigation 2 Diabetes Study). Am J Cardiol., 104 (1): 52-8. 